mycin to any one biological activity. However, the graph does indicate a uniformity of egg numbers at concentrations of $1 / 1,000,000$ and $1 / 10,000,000$. This tends to suggest a stabilization of reproductive (egg laying) capacity at the two concentrations, showing that an optimum effect has been reached. Further work is definitely necessary for a better understanding of these data.

We wish to thank Dr. C. L. Duddington for his encouragement during the work, and also the Department of Chemistry and Biology at The Polytechnic for providing the necessary equipment and facilities.

Biological Laboratories,

$$
\text { C. O. R. Everard }
$$
The Polytechnic,

Regent Street, London, W.1.

U.S. Department of Agriculture,

William A. Feder* Orlando, Florida.

* Senior Postdoctoral Fellow of the U.S. National Science Foundation. Taylor, A. L., Julius Feldmesser, and Feder, W. A., Plant Dis. Reptr., 41 (6), 527-530 (1957).

\section{Vivipary in Eleusine Indica (L) Gaertn}

Aт two localities near Brisbane, plants of Eleusine indica, an annual grass, have been observed with inflorescences bearing proliferated spikelets. Such plants were rare and in every instance bore normal as well as proliferated spikelets.

The subtending glumes of the proliferated spikelets were normal but all or some of the lemmas were modified. The modified lemmas varied from near normal to typically leaf-shaped with well-developed sheathing bases and ligules. Usually only the upper lemmas were modified whilst those at the base of the spikelet subtended flowers, which though structurally complete failed to mature. The degree of development of the palea and flower was inversely proportional to the amount by which the lemma was modified. In some proliferated spikelets the lower flowers were replaced with vegetative shoots. The numbers of florets present in samples of normal and proliferated spikelets are summarized in Table 1.

Table 1. NJMBERS OF FLORETS PER SPIKELET IN NORMAL AND Spikelet PROLIFERATED SPIKELETS OF Eleusine indica

normal proliferated

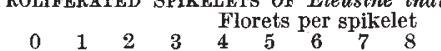

9

Structurally the proliferated spikelets of $E$. indica closely resemble those of certain viviparous forms of Festuca ovina ${ }^{2}$. It is therefore suprising that whereas the proliferated spikelets or bulbils of $F$. ovina grow quite readily into new plants those of $E$. indica seem incapable of further growth if detached from the parent plant. The bulbils in $E$. indica have not been observed to act as propagules in the wild and they have failed to grow when kept under a variety of different cultural conditions. Similar bulbils from inflorescences of $E$. corocana are reported to grow readily if planted ${ }^{4}$. In view of the statement by Gustaffson $^{3}$ that no viviparous grass species is diploid, it is interesting to note that $E$. indica is diploid and E. corocana is tetraploid ${ }^{1}$.

The only other record of vivipary in $E$. indica is from Foochow in China ${ }^{4}$. Both Foochow and Brisbane are at similar latitudes and so have similar daylength régimes. This may be significant as day-length has been shown to be an important factor controlling day-length in Deschampsia flexuosa ${ }^{5}$. Further data are required on the occurrence of vivipary in $E$. indica and $E$. corocana to determine whether or not the phenomenon is geographically widespread. Over a period of years in Southern Nigeria, a region of short daylengths, no proliferated spikelets were observed on either of the above species of Eleusine though both species are common there.

Botany Department,

H. T. CLIFFORI

University of Queensland, Brisbane.

${ }^{1}$ Darlington, C. D., and Wylie, A. P. (London, 1956).

2 (xustafsson, A., Lunds. Vniv. Arsskrift, 42, 66 (1946).

${ }^{3}$ Gustafsson, A., Lunds Univ. Arsskrift, 43, 71 (1947).

${ }^{4}$ Li, L., Bot. Gaz., 111, 358 (1950)

Schultz, G. E., Bot. Zhurn. S.S.S.R., 24, 197 (1939) from Biol. Abst., 16 3711 (1942)

\section{An Electron-Microscopic Study of Spores of Morphological Variants of Streptomyces erythreus strains}

ThE morphological heterogeneity of lower fungi, based on the different intensity of formation of aerial mycelium and conidia, was found in most of the representatives of the Fungi Imperfecti and was deseribed by Hansen ${ }^{1}$ as the 'dual phenomenon'. According to Lindegreen and Andrews' the 'dual phenomenon' represents a case of simple heterocaryosis. Heterocaryosis is exhibited by Actinomycetes as well, as shown by Bradley and Lederberg ${ }^{3}$.

It was shown indirectly in a previous communication ${ }^{4}$ that heterocaryosis was one of the causes of degeneration of the high-production strain Streptomyces erythreus VUAM. Electron-microscope studies are herewith described as applied to the spores of morphological variants of the strain Streptomyces erythreus VUAM and of two morphologically and productively stable strains Streptomyces erythreus No. 58/100 and No. 20-V-107. Spores were harvested from a number of morphologically different colonies. obtained by cultivation on complex media ${ }^{4}$. In the case of the rapidly degenerating strain of Streptomyces erythreus asporogenic colonies were detected and in addition to them three types of colonies displaying morphological differences of their spores. Two types of colonies characterized by the formation of rich aerial mycelium and by a good production activity, formed chains of oval spiny spores. The spines of the spores were somewhat widened at the base and reached the length of $0.9 \mu$ (cf. Fig. 1). Colonies of the third type, characterized by a poor aerial mycelium and by a low or completely absent production activity, contained in their hyphæ several morphologically different types of spores : chains of solely oval, richly spiny spores (as in Fig. I), chains of solely rectangular, spineless spores (Fig. 2), and chains comprising both oval and rectangular spores with a minute number of spines (Fig. 3).

Stable strains of Streptomyces erythreus forming two morphological types of colonies along with asporogenic types and characterized by the formation of a rich aerial mycelium with a good production activity, produced spores of but one morphological type, that is, oval spores with thick spines. In these strains it was impossible to detect the presence of colonies characterized by a poor aerial mycelium as found in the above-described rapidly degenerating strain Streptomyces erythreus VUAM.

The finding that three Streptomyces erythreus strains of different origin formed oval spiny spores is not in agreement with the results of Ettlinger 